\title{
Politique
}

Politique

\section{L'immigration. Pourquoi faire? de Denise Helly, Québec, Institut québécois de recherche sur la culture, 1992, 229 p.}

\section{Daniel Latouche}

Numéro 23, hiver 1993

Tendances de la science politique au Québec

URI : https://id.erudit.org/iderudit/040754ar

DOI : https://doi.org/10.7202/040754ar

Aller au sommaire du numéro

Éditeur(s)

Société québécoise de science politique

ISSN

0711-608X (imprimé)

1918-6584 (numérique)

Découvrir la revue

Citer ce compte rendu

Latouche, D. (1993). Compte rendu de [L'immigration. Pourquoi faire? de Denise Helly, Québec, Institut québécois de recherche sur la culture, 1992, 229 p.]

Politique, (23), 221-224. https://doi.org/10.7202/040754ar d'utilisation que vous pouvez consulter en ligne.

https://apropos.erudit.org/fr/usagers/politique-dutilisation/ 


\section{L'immigration. Pourquoi faire?}

de Denise Helly, Québec, Institut québécois de recherche sur la culture, 1992, 229 p.

Cette étude est le fruit de 41 entrevues réalisées entre mars 1986 et février 1987 auprès de personnes «établies dans les villes de Québec et de Montréal» et dont la principale caractéristique était d'avoir contribué, à des degrés divers, à la «production de représentations de l'immigration dans des documents publics largement distribués". II s'agit donc de ce qu'on appelait à l'époque une enquête auprès d' kélites" grâce à la technique des entrevues en profondeur. Chaque entretien a été conduit par l'auteure elle-même et durait plus de deux heures. À l'origine, le projet prévoyait une enquête similaire auprès de milieux dont les représentations de l'immigration $n$ 'ont pas nécessairement été reproduites dans des documents écrits ou qui sont localisés en dehors des deux grands centres urbains. Cette partie a malheureusement dû être abandonnée, probablement faute de temps ou de moyens, ou les deux à la fois.

Le temps écoulé entre les entrevues et la publication de ce livre, six années, et surtout la période particulière où elles ont été réalisées - au moment où le Parti québécois était renvoyé à ses devoirs - fait-il de ce livre un livre daté ? Oui et non, mais finalement cela n'a aucune importance. Ce qui en fait plutốt l'intérêt, c'est précisément qu'il constitue une photographie de ce que certaines élites québécoises pouvaient penser au moment même où le débat sur l'immigration prenait ce virage démographique qui le caractérise encore aujourd' hui. On peut dire que l'auteure a eu de la chance. Deux ans plus tôt et on était encore dans cette période triomphante où, suite à la loi 101 et au Plan d'action du Parti québécois et de son ministre des Communautés culturelles, M. Gérald Godin, tout allait, sinon pour le mieux, du moins pour le «moins pire" dans le meilleur des mondes de l'intégration des immigrants. Deux ans plus tard, au moment des entrevues, tout a basculé. Le 
projet québécois a perdu de sa belle assurance et on commence donc à réaliser que c'est sur la question de l'immigration, et non plus sur celle de la politique ou de l'économique, que l'avenir du Québec va se jouer. C'est à ce moment précis que commence l'enquête. Six ans plus tard, les termes du débat $n$ 'ont guère changé et l'étude de Denise Helly nous permet d'en comprendre le déroulement.

La configuration théorique du livre a l'immense mérite d'être simple et d'être présentée par l'auteure en des termes aussi simples que pénétrants. Cela nous change de certains livres. Une représentation, explique-t-elle, peut être définie comme une vision explicative de la réalité qui ne s'expose pas au processus d'expérimentation ou de réfutabilité. Dans le domaine de l'immigration, ces représentations s'articulent autour de deux séries de paramètres. II y a d'abord ceux qui entourent la frontière externe de la société en question et qui définissent le fait physique d'immigrer et ce qu'il implique pour la société d'accueil. Pour quelles raisons une société envisage-t-elle d'accueillir des "étrangers"? Au nom de quels principes le fait-elle? Comment envisage-t-elle de s'y prendre pour "contrôler" ses frontières ?

La seconde série de paramètres concerne la frontière interne, celle qui définit les fondements et les caractéristiques de l'identité collective de la société d'accueil. Qui sont ces immigrés et où s'insèrent-ils au sein du groupe ? Font-ils ou non partie du projet ?

Pour ce qui est des perceptions de la frontière externe et du pourquoi de l'immigration, Denise Helly divise ses répondants en deux groupes : les populationnistes pour qui l'argument démographique est primordial et les économistes pour lesquels il s'agit surtout d'accroître la compétitivité de la main-d'œuvre québécoise. Ce clivage se traduit par des visions différentes des niveaux d'immigration souhaitables ainsi que des critères par lesquels les immigrants doivent être choisis. Mais par delà ces différences, somme toute prévisibles, le plus étonnant, c'est la vision essentiellement utilitaire de l'immigration qu'entretiennent les deux groupes. On n'est prêt à accepter sur le territoire du Québec que des individus jugés «utiles" à la société québécoise et c'est uniquement en fonction de clivages internes à cette société qu'on élabore ses 
perceptions de l'immigration. Comme le souligne avec justesse l'auteure, l'immigration n'est que rarement pensée comme composante d'une situation internationale et encore moins par rapport aux intérêts des autres régions canadiennes.

Un autre élément de la frontière externe ressort comme primordial - et surprenant, pourrions-nous ajouter. Cette frontière est perçue par la grande majorité des répondants comme une frontière permanente et définitive. Contrairement au débat qui a cours dans la majorité des pays européens, il s'est trouvé bien peu de «définisseurs de situation» québécois pour discuter d'immigration en termes de travailleurs temporaires et de retour au pays d'origine. Les immigrants sont ici pour rester et il ne saurait être question de les pénaliser au chapitre des droits individuels, sociaux ou politiques. Les immigrants sont peut-être de mauvais Québécois, mais ils sont des Québécois instantanés et c'est en fonction de l'irréversibilité de leur présence ici qu'on les juge.

Trois principaux courants de pensée distinguent les répondants - rappelons de nouveau qu'ils ne sont que 41 quand ils définissent le statut des immigrés au sein de la société québécoise. II y a d'abord ceux - en apparence majoritaires puisqu'ils sont 20 - qui défendent un projet francophone, autonomiste ou indépendantiste, et qui voient dans les immigrés des alliés potentiels. Un deuxième groupe les considère comme de simples citoyens égaux devant la loi et qui participent comme tous les autres à la vie d'une société définie ici exclusivement comme une aire de libre circulation. Et puis un troisième groupe - ils ne sont cependant que quatre à partager ce point de vue - les considère comme des radversaires et des citoyens de seconde classe d'un État ethnique réservé aux francophones de souche ou assimilés".

Le livre se termine par des propos malheureusement trop brefs sur les différentes conceptions de la démocratie que véhiculent ces différentes visions. Ses commentaires sur la tradition républicaine québécoise, une République sans peuple suggère-t-elle, sont à lire et à méditer.

Certes, il y aurait beaucoup à re-dire sur ce livre et sur un ton qui frôle parfois la condescendance et le moralisme. De toute évidence, Denise Helly n'est guère à l'aise avec des 
élites qui incarnent «la continuité affective et historique qui constitue la nation». Mais cette distance critique a le mérite de nous avoir donné l'un des meilleurs livres sur la «carte mentale", le «mind set" dirait-on à Paris, des Québécois sur l'immigration.

Daniel Latouche INRS - Urbanisation 